\title{
Treatment of Dacron Grafting Dilatation with Endovascular Stent Graftıng
}

\author{
Murat Ugurlucan, MD ${ }^{1 *}$, Didem Melis Oztas, MD', Yilmaz Onal, MD², Cagla Canbay, MD', \\ Mehmet Buget, $\mathrm{MD}^{5}$, Bulent Acunas, MD², Ufuk Alpagut, $\mathrm{MD}^{1}$ \\ ${ }^{1}$ Department of Cardiovascular Surgery, Istanbul University Istanbul Medical Faculty, Istanbul, Turkey \\ 2 Department of Radiology, Istanbul University Istanbul Medical Faculty, Istanbul, Turkey \\ ${ }^{3}$ Department of Thoracic Surgery, Duzce Ataturk State Hospital, Istanbul, Turkey \\ ${ }^{4}$ Department of General Surgery, Duzce Ataturk State Hospital, Istanbul, Turkey \\ ${ }^{5}$ Department of Anesthesia, Istanbul University Istanbul Medical Faculty, Istanbul, Turkey
} Omer Ali Sayin, MD'1, Mehmet Barburoglu, MD², Muslum Ercument Filik, MD³, Deniz Ocal, MD4,

\begin{abstract}
Dacron grafts are frequently used during surgical revascularization procedures. Complications including graft thrombosis and infection are well known; however, aneurysm formation is extremely rare. In this report, we describe dilatation of a Dacron graft detected four years after aortobifemoral bypass procedure in a 50-year-old male patient who was treated with endovascular stent grafting.

Copyright @ 2016 Science International Corp.
\end{abstract}

\section{Key Words}

Peripheral arterial disease - Bypass - Dacron graft • Dilatation - Endovascular stent graft

\section{Introduction}

Surgical revascularization procedures are effective therapies for patients with peripheral arterial diseases. Dacron grafts are frequently used during these procedures. Infection, graft thrombosis, and pseudoaneurysm are well known complications. Although reported in the literature, rupture or aneurysm formation is a very rare complication with knitted Dacron

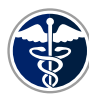

Fax +1 2037853552

E-Mail: aorta@scienceinternational.org

http://aorta.scienceinternational.org

\author{
(c) 2016 AORTA \\ Published by Science International Corp. \\ ISSN 2325-4637 \\ Accessible online at: \\ http://aorta.scienceinternational.org
}

grafts [1,2]. The latter may be completely asymptomatic and be diagnosed with radiologic techniques or present as a pulsatile mass and its consequences [3].

In this report, we present a patient with dilatation of the Dacron graft following aortobifemoral bypass surgery together with a management strategy for the disorder.

\section{Case Presentation}

A 50-year-old male patient presented to our institution with left leg pain and a pulsatile mass in left femoral region. He had undergone an aortobifemoral bypass procedure with an $18 \times 9-\mathrm{mm}, 45-\mathrm{cm}$ knitted polyester vascular graft (FlowNit Bioseal, Knitted Polyester Vascular Graft, L: 45 cm, D: $18 \times 9$ mm; collagen-coated, JOTEC Vascular Prosthesis, JOTEC $\mathrm{GmbH}$, Hechingen, Germany) for the treatment of aortoiliac occlusive disease in 2011. He was an active smoker but did not have other comorbidities. He had been asymptomatic until he presented to the clinic with claudication of the right leg in 2013. Control computed tomography (CT) angiography revealed aneurysm formation and thrombosis of the right

* Corresponding Author:

Murat Ugurlucan, MD

Department of Cardiovascular Surgery

Istanbul University Istanbul Medicine Faculty

Millet Caddesi, Capa, Fatih, Istanbul, Turkey

Tel.: +90 53082511 22; Fax: +90 21253422 32; Email: muratugurlucan@yahoo.com 
common femoral artery (Figure 1A1, 1A2, 1A3). Prior to operation planning, the patient had undergone conventional angiography in 2014, which indicated complete thrombosis of the right limb of the graft (Figure 1B). Angiography performed in 2013 and 2014 also showed dilatation of the Dacron graft (Figure 1A1, 1B). He underwent crossover bypass with a saphenous vein from the left limb of the graft to the right profunda femoral and superficial femoral arteries. A control CT angiography showed patent bypass grafts together with increased diameter of the Dacron graft with a body size of $28.5 \mathrm{~mm}$ and $13.3-\mathrm{mm}$ leg size (Figure 1C1, 1C2). He presented with an enlarging pulsatile mass at the left femoral region 6 months postoperatively. CT revealed further dilatation of the Dacron graft (29.4-mm body size, 14-mm leg size) and a 50-mm diameter left femoral aneurysm (Figure 1D). All the radiographic measurements were performed by the radiologists with ExtremePACS viewer software (Hacettepe Teknokent A.S., Ankara, Turkey). We planned surgical correction of the left femoral aneurysm and endovascular security for the dilated Dacron graft after obtaining the patient's consent.

The operation was performed with sedation and local infiltration anesthesia with a $50 \%$ mixture of prilocaine hydrochloride and bupivacaine hydrochloride. A standard longitudinal femoral incision was performed, and the dilated leg of the aneurysm, common, profunda, and superficial femoral arteries were dissected. There was no sign of infection or any other cause to explain the progressive dilatation of the Dacron material. A Linderquist extrastiff guide wire 0.035 (Cook Medical Inc., Bloomington, IN, USA) was positioned at the ascending aorta through a 5 French $(F)$ sheath inserted in to the left leg of the graft through the aneurysm. A $5 \mathrm{~F}$ sheath was inserted percutaneously through the right brachial artery. A $5 \mathrm{~F}$ pigtail catheter was directed for angiographic monitoring of the stent graft position though this $5 \mathrm{~F}$ sheath. After intravenous administration of 5,000 units of heparin, we inserted the main body (size: 23 $\times 14 \times 105$ mm, Medtronic Endurant Stent Graft System, Santa Roja, CA, USA) and leg extension (size: 16 $\times 16 \times 120$ mm, Medtronic Endurant Stent Graft System) through the left leg of the aortobifemoral Dacron graft and positioned and expanded the infrarenal aorta covering the dilated Dacron graft until the crossover femoral bypass. The aneurysm at the femoral region containing the dilated Dacron graft segment was then resected, and arterial continuity was provided with a ringed 8-mm expanded polytetrafluoroethylene graft (FUSION Vascular Graft, Maquet Cardiovascular, Wayne, NJ, USA) that was interposed between the left limb of the bypass graft and left common femoral artery.

The postoperative course was uneventful, and the patient was discharged symptom free from the hospital on the fifth postoperative day. He has been doing well for 2 years and receives acetylsalicylic acid, atorvastatin, pentoxyphylline, and clopidogrel. The patient was investigated for systemic connective disorders and found to be negative. Control CT confirmed successful surgical and endovascular treatment (Figure 2).

\section{Discussion}

Dacron grafts are frequently used during the treatment of aortic and peripheral arterial pathologies. Different types of Dacron grafts such as knitted, woven, flat, and swollen are available in the market. While woven grafts are generally used for thoracic and abdominal aortic aneurysm repairs and aortic replacement, knitted grafts are used for arterial bypass procedures of the aorta, iliac, common femoral, and superficial femoral arteries. Graft patency rates are quite promising in selected patients and revascularization locations; however, the procedures are not event free [4]. Complications include infection, graft thrombosis, pseudoaneurysm, aneurysm or dilatation, and rupture [5].

The intrinsic Dacron graft failure rate ranges from $0.5-3 \%$ [6]. The most common complications are infection and graft thrombosis; Dacron graft aneurysms are very rare disorders. This complication is reported to occur in $1-3 \%$ of patients with graft replacement and are usually seen 4-6 years after surgery [5]. The first report on this disorder mentioned aneurysmal dilatation of Dacron graft 5.5 years after surgical treatment [7]. Etiology of anastomotic complications are variable and include infections, surgical procedure problems, collagen tissue disorders, and atherosclerotic diseases. In contrast, a nonanastomotic aneu- 

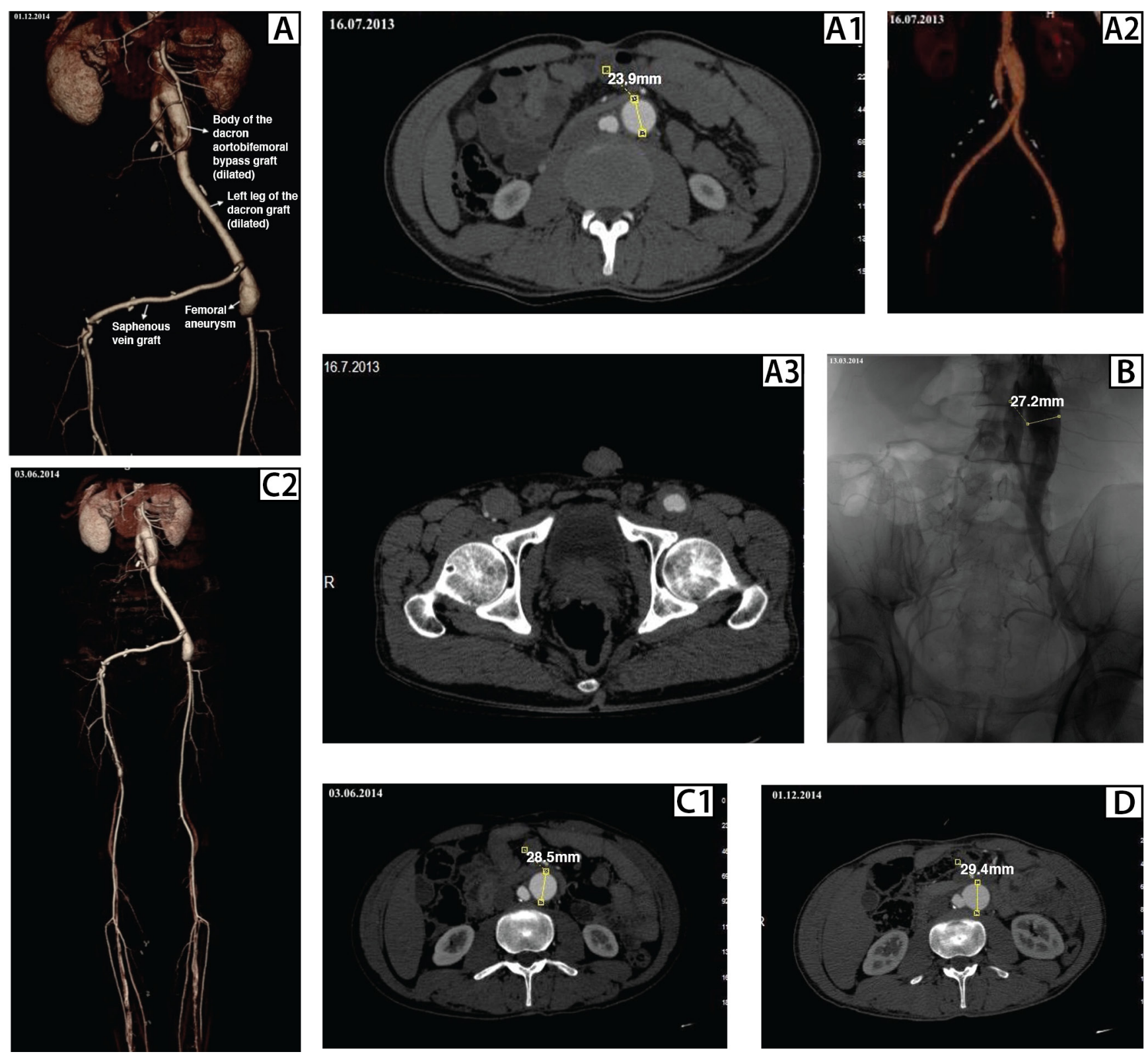

Figure 1. Preoperative computed tomography (CT) angiography showing Dacron graft dilation (29.4-mm body size, 14-mm leg size) and a 50-mm diameter left femoral aneurysm together with crossover femoral bypass with saphenous vein grafts. Panel A1: Control CT in 2013 revealed dilatation of the Dacron graft. Panel A2: Both legs of the Dacron were patent, but the right common femoral artery was thrombosed. Panel A3: CT shows a thrombosed right femoral artery and dilated left femoral artery. Panel B: Prior to operation planning, the patient underwent conventional angiography in 2014, which indicated complete thrombosis of the right limb of the graft and further dilatation of the Dacron graft (body size $27.2 \mathrm{~mm}$ ). Panels C1-C2: A control CT angiography in 2014 showed an increase in diameter of the Dacron graft with a body size of $28.5 \mathrm{~mm}$ and $13.3-\mathrm{mm}$ leg size. Panel D: When the patient presented with an enlarging pulsatile mass at the left femoral region 6 months after the operation, the CT angiography revealed further dilatation of the Dacron graft (axial view, 29.4-mm body size). 


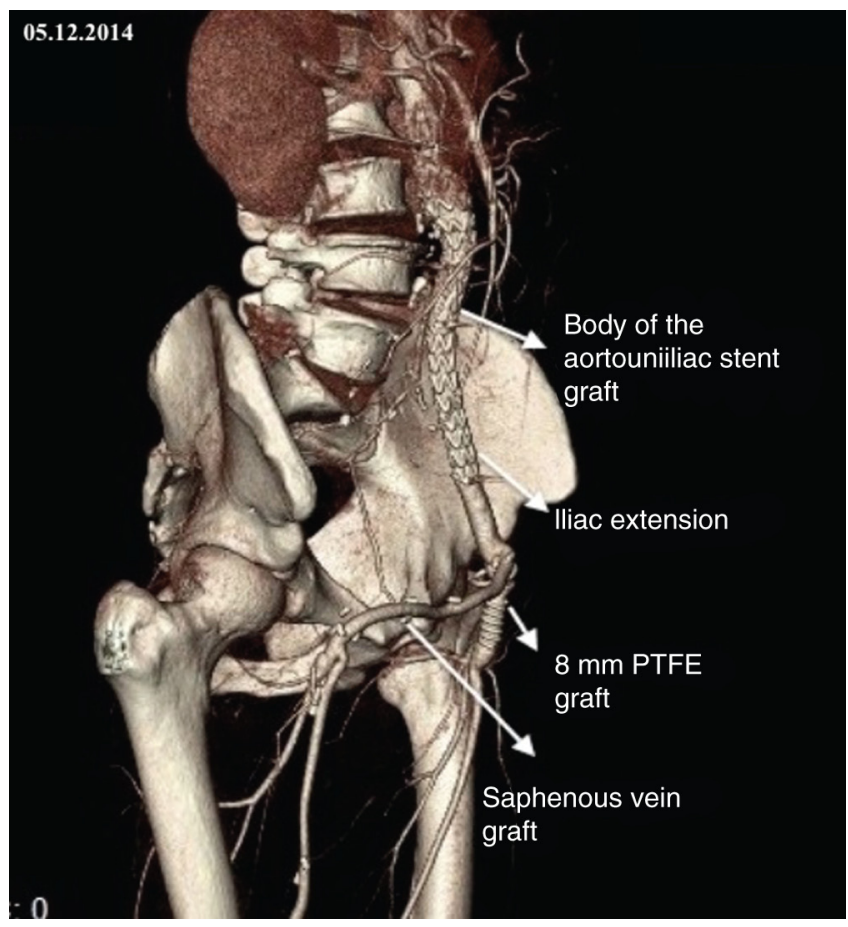

Figure 2. Postoperative control computed tomography angiography.

rysm is usually secondary to prosthetic graft failure. It may cause graft dilatation and even worse, rupture without intrinsic factors and external trauma [8]. The etiology may be fabrication faults, sterilization errors, biodeterioration due to infection or hematomas, and material fatigue $[9,10]$. Aneurysms are commonly seen in the aortoiliac for aortofemoral bypass grafts and the costal arch in axillofemoral bypass grafts. Considering these locations, medical stress on the grafts is considered a facilitating factor [11].

The risk of aneurysmal rupture is very rare but fatal. One report included scanning electron microscopy findings that showed deterioration of the polyester filaments around the guideline [12]. The guideline and remeshing line are two weak points in Dacron grafts, and graft ruptures are commonly seen in these areas [13]. Rupture may also be seen in the long term, so it is advisable that all dilated portions should be repaired surgically or with endovascular methods.
Most cases may present with generalized dilation. However, the literature includes very rare disorders like multiple saccular aneurysms [14]. CT is a useful and reliable imaging method and commonly used for diagnosing graft dilatation [3].

Therapy modalities include surgical and endovascular treatments, with the latter typically preferred to open surgery. It reduces mortality, morbidity, and hospital stay length and avoids open surgery complications [2]. In the present case, we detected Dacron graft dilatation together with a femoral aneurysm comprising both the native artery and the leg of the graft. Preventing further Dacron graft dilation was achieved with endovascular therapy, which was also a more comfortable and safe therapy option for compared with conservative surgical graft removal and replacement.

\section{Conclusion}

In conclusion, the risk of aneurysm and rupture is very rare but known complications with Dacron grafts used for arterial reconstructions. Treatment should be considered for dilated portions of the Dacron prosthesis. Endovascular stent graft repair seems an easier and more comfortable therapy option in patients with Dacron graft aneurysms.

\section{Acknowledgment}

The export director and international product specialist of the JOTEC company were informed about the issue, and the international sales director replied that the Turkish distribution partner would contact us, but this has not yet happened.

\section{Conflict of Interest}

The authors have no conflict of interest relevant to this publication.

Comment on this Article or Ask a Question 


\section{References}

1. Nunn DB, Carter MM, Donohue MT, Hudgins PC. Postoperative dilation of knitted Dacron aortic bifurcation graft. J Vasc Surg. 1990;12:291-297. DOI: 10.1016/07415214(90)90150-9

2. Ofer A, Nitecki S, Hoffman A, Engel A. Dacron graft aneurysm treated by endovascular stent-graft. Cardiovasc Intervent Radiol. 2001;24:60-64. DOI: 10.1007/ s002700001722

3. Goëau-Brissonnière $O A$, Qanadli $S D$, Ippoliti A, Pistolese GR, Coggia M, Pollock JG. Can knitting structure affect dilation of polyester bifurcated prostheses? A randomized study with the use of helical computed tomography scanning. J Vasc Surg. 2000;31:157-163. DOI: 10.1016/S07415214(00)70077-2

4. Nevelsteen A, Wouters L, Suy R. Aortofemoral dacron reconstruction for aorto-iliac occlusive disease: a 25-year survey. Eur J Vasc Surg. 1991;5:179-186. DOI: 10.1016/ S0950-821X(05)80685-1

5. Han I, Shigematsu H, Nunokawa M, Matsuzaki $\mathrm{H}$, Iwata K, Nakamura $\mathrm{S}$, et al. Nonanastomotic aneurysm formation in a Dacron arterial graft: report of a case. Surg Today. 1994;24:1007-1010. DOI: 10.1007/ BF02215815
6. Khaira HS, Vohra H. True aneurysm in a femoro-popliteal Dacron graft-a case report and literature review. Cardiovasc Surg. 2002;10:644-646. DOI: 10.1016/S09672109(02)00064-9

7. Knox WG. Aneurysm occurring in a femoral artery Dacron prosthesis five and one-half years after insertion. Ann Surg. 1962;156:827-830. DOI: 10.1097/00000658-196211000-00018

8. Yamamoto $S$, Hoshina $K$, Kimura $H$, Okamoto H, Shigematsu K, Miyata T, et al. Clinical analysis of nonanastomotic aneurysms of implanted prosthetic grafts. Surg Today. 2014;44:1855-1862. DOI: 10.1007/ s00595-014-0888-2

9. Doğan K, Ersoy G, Gökgöz Ş. Dacron Greft Rüptürü. Turkish J Thorac Cardiovasc Surg. 1994;2:59-61.

10. Yamaguchi $S$, Asakura T, Miura $S$, Ohki $T$, KanaokaY, Ohta H, etal. Nonanastomotic rupture of thoracic aortic Dacron graft treated by endovascular stent graft placement. Gen Thorac Cardiovasc Surg. 2013;61:414-416. DOI: 10.1007/s11748-012-0158-4

11. Ryugo $M$, Yasugi $T$, Nagashima $M$, Izutani H, Okamura T, Shikata F, et al. Pseudoaneurysm in the Left Groin due to Ruptured Knitted Dacron Graft. Ann Vasc
Dis. 2011;4:154-156. DOI: 10.3400/avd. cr.10.00018

12. Kawajiri $\mathrm{H}$, Watanabe $T$, Kanda $\mathrm{K}$, Yaku $\mathrm{H}$. Longitudinal rupturing of a knitted Dacron graft 30 years after its implantation. Interact Cardiovasc Thorac Surg. 2014;18:861863. DOI: 10.1093/icvts/ivu053

13. Chakfe N, Riepe G, Dieval F, Le Magnen JF, Wang L, Urban E, et al. Longitudinal ruptures of polyester knitted vascular prostheses. J Vasc Surg. 2001;33:1015-1021. DOI: $10.1067 /$ mva.2001.113493

14. Ratto GB, Truini M, Sacco A, Canepa G, Badini A, Motta G. Multiple aneurysmal dilatations in a knitted dacron velour graft. J Cardiovasc Surg (Torino). 1985;26:589-591. PMID: 2933412

Cite this article as: Ugurlucan $M$, Oztas DM, Onal Y, Canbay C, Sayin OA, Barburoglu M, Filik ME, Ocal d, Buget M, Acunas B, Alpagut U. Treatment of Dacron Grafting Dilatation with Endovascular Stent Graftıng. AORTA (Stamford). 2016;4(5):162-166. DOI: http://dx.doi.org/10.12945/j. aorta.2016.15.034 